\title{
PLASMA-ASSISTED SYNTHESIS OF NON-STOICHIOMETRIC NANOCERIA POWDER FROM CERIUM CARBONATE HYDROXIDE $\left(\mathrm{CeCO}_{3} \mathrm{OH}\right)$
}

\author{
Yuan-Pei Lan ${ }^{1,2,3}$, Hong Yong Sohn ${ }^{2 *}$, and Qingcai Liu ${ }^{1}$ \\ ${ }^{1}$ College of Materials Science and Engineering, Chongqing University, \\ 174 Shazheng Road, Shapingba, Chongqing 400044, China. \\ ${ }^{2}$ Department of Metallurgical Engineering, University of Utah, Salt Lake City, \\ UT 84112, United States. \\ ${ }^{3}$ Y.-P. Lan is currently Assistant Professor at Guizhou University, Guiyang,
} China

Received 26.07.2017

Accepted 30.08.2017

\begin{abstract}
Highly non-stoichiometric nanoceria was synthesized for the first time by thermal plasma from the precursor cerium carbonate hydroxide. The particle size was approximately $60 \mathrm{~nm}$ according to measurement by TEM. The nanoceria synthesized with $25 \mathrm{~kW}$ plasma power with argon as the carrier gas had the largest concentration of oxygen vacancies, follow by that produced with $20 \mathrm{~kW}$ with hydrogen as the carrier gas. XRD results indicated that the $\mathrm{CeO}_{1.66}$ phase was present with mostly nonstoichiometric ceria $\mathrm{CeO}_{2-\mathrm{x}}$ in these two products. SEM and TEM images showed that most of the particles were of irregular shape, while some triangular particles were also present. Raman spectra revealed that the $\mathrm{F}_{2 \mathrm{~g}}$ mode of synthesized nanoceria powders had a remarkable downshift of $7.9-10.5 \mathrm{~cm}^{-1}$ relative to the peak for single crystal ceria located at $466.0 \mathrm{~cm}^{-1}$. The Raman downshift was explained by the increase in ionic radius upon $\mathrm{Ce}^{4+}$ reduction to $\mathrm{Ce}^{3+}$. XPS results indicated that the $\mathrm{Ce}^{3+}$ content on the surface of the synthesized nanoceria was in the range of $15-30 \%$, depending on the plasma power and carrier gas composition. Both the Raman and XPS spectra showed numerous oxygen vacancies in the nanoceria. The results of this work indicated that the oxygen vacancy formation occurred when the $\mathrm{CeO}_{2}$ formed from the oxidation of cerium carbonate hydroxide was reduced by the hydrogen as well as the high temperature of the plasma. This investigation has verified that plasma treatment provides a promising method for the synthesis of nanoceria powder with high oxygen vacancies.
\end{abstract}

*Corresponding author: Hong Yong Sohn,h.y.sohn@utah.edu 
Keywords: Thermal plasma; nanoceria; non-stoichiometry; oxygen vacancies.

\section{Introduction}

Cerium has a ground state electron in the $4 \mathrm{f}$ orbital $\left(\mathrm{Xe} 4 \mathrm{f}^{1} 5 \mathrm{~d}^{1} 6 \mathrm{~s}^{2}\right)$, which is responsible for the reduction/oxidation behavior when cycling between its two ionic

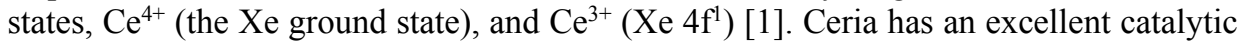
activity for converting $\mathrm{CO}$ in automobile exhaust gas to $\mathrm{CO}_{2}$ based on its redox property [2]. Ceria is also used to produce $\mathrm{CO}$ or $\mathrm{H}_{2}$ with solar energy [3]. It is also used for chemomechanical polishing and planarization. It has been theorized that the $\mathrm{Ce}^{4+}$ to $\mathrm{Ce}^{3+}$ transition and the presence of surface cerium hydroxyl group are responsible for the catalytic property of ceria $[4,5]$. Additionally, ceramic materials based on ceria hold much promise for the production of electrolyte for solid oxide fuel cells, and reportedly have a better ion conductance than $\mathrm{Y}_{2} \mathrm{O}_{3}$ stabilized $\mathrm{ZrO}_{2}$ (YSZ) $[6,7]$.

Because of the redox property due to the transition between its cations, ceria easily forms a non-stoichiometric state, $\mathrm{CeO}_{2-\mathrm{x}}$, in which $0<\mathrm{x}<0.5$. Nonstoichiometric ceria can be produced by chemical reduction [8], X-ray exposure [9], or a high temperature [10]. Mudiyanselage et al. [11] noted that the Ce3+ plays an important role on $\mathrm{CO}$ oxidation by providing an adsorption site for CO. Recently, Gao and coworkers [8] reported that ceria with a larger $\mathrm{Ce}^{3+}$ fraction enhanced $\mathrm{CO}$ conversion. The oxygen mobility in these materials is based on vacancy hopping $[12,13]$. The energy levels associated with the formation of single and double vacancies were found to be equal to 4.1 and $4.7 \mathrm{eV}$, respectively [14]. The electron carrier concentration $\mathrm{Ce}_{\mathrm{Ce}}^{\prime}$, which determines the conductive property of non-stoichiometric ceria, is proportional to $x$ in $\mathrm{CeO}^{2-x}[15]$. The oxygen vacancies present in non-stoichiometric ceria are related to many unique properties of ceria: For example, the oxygen storage capacity increases with a number of oxygen vacancies [16]. Chemical stability and high mobility of oxygen vacancies [17] make ceria a good candidate for fast oxygen sensors at high temperatures. Additionally, the oxygen vacancy in ceria also plays an important role in its stable grain boundary structures [18].

Nanoceria particles have been synthesized by the following different methods: hydrolysis [19], precipitation [20, 21], thermal decomposition [22], combustion- or flame-synthesis [23], micro-emulsion technique [24] and hydrothermal process [25]. Annually, approximately 10000 metric tons of nanoceria are produced [1].

A thermal plasma is an excellent tool for synthesizing nanostructured materials because its high temperature can rapidly vaporize or decompose precursors and form nanostructure materials. Nanoparticles of oxides and ceramic materials, such as $\mathrm{TiO}_{2}$ [26] and $\mathrm{TiO}_{2}$-based materials [27], $\mathrm{Y}_{2} \mathrm{O}_{3}$ stabilized $\mathrm{ZrO}_{2}$ (YSZ) [28] and spherical alumina particles [29], SiC nano-fibers [30] and boron nitride (BN) nanotubes [31], have been synthesized by the use of thermal plasma. It was reported [32] that stable non-stoichiometric ceria was prepared using thermal plasma, but little has been reported on the plasma synthesis of such particles from precursors.

On the other hand, cerium carbonate hydroxide $\mathrm{CeCO}_{3} \mathrm{OH}$ has been reported to be decomposed into spherical nanoceria particles by hydrothermal treatment in glucose solutions [33] and into micro-sized particles by simply heating it in the air [34]. Based on this previous work, thermal plasma was considered to offer an excellent means to decompose cerium carbonate hydroxide for the synthesis of nanoceria particles. Using 
this method, nanoceria powder with a high concentration of oxygen vacancies was prepared in this work. The effects of plasma power and gas atmosphere were investigated, and the properties and oxygen vacancy levels of the synthesized nonstoichiometric nanoceria were studied by the use of several instrumental analysis techniques.

\section{Experimental}

Materials

$\mathrm{Ce}_{2}\left(\mathrm{CO}_{3}\right)_{3} \cdot \mathrm{xH}_{2} \mathrm{O}$ from Sigma-Aldrich (St. Louis, Missouri, U.S.A.) was used as the precursor after first milling it to powder with an average particle size of less than 20 $\mu \mathrm{m}$ followed by drying the milled powder at $100{ }^{\circ} \mathrm{C}$ for 12 hours to form cerium carbonate hydroxide, $\mathrm{CeCO}_{3} \mathrm{OH}$, following the procedure reported in the literature [35]. Methods

The DC plasma reactor used in this work consisted of a plasma generator with a downward plasma torch, a cylindrical reactor, a cooling chamber, a precursor feeding system, and a powder collector, as shown in Fig. 1. More details of the plasma reactor can be found in previous publications $[28,36]$. The $\mathrm{CeCO}_{3} \mathrm{OH}$ powder was fed into the reactor at a rate of $0.75 \pm 0.04 \mathrm{~g} / \mathrm{min}$, carried by a $3.5 \mathrm{~L} / \mathrm{min}$ flow of argon $\left(25^{\circ} \mathrm{C}\right.$ and $86.1 \mathrm{kPa}$ atmospheric pressure at Salt Lake City). Another $39 \mathrm{~L} / \mathrm{min}$ argon flow was used as the plasma gas. The plasma torch power was set at $15 \mathrm{~kW}, 20 \mathrm{~kW}$, and $25 \mathrm{~kW}$. After the powder was fed into the reactor for $12 \pm 1$ minutes, blue non-stoichiometric ceria particles were collected on a Teflon-coated polyester filter with a pore size of 1 $\mu \mathrm{m}$ that was placed in the off-gas stream.

Additional experiments were conducted with carrier gases of different compositions under $20 \mathrm{~kW}$ plasma power. One carrier gas was a mixture of $1.75 \mathrm{~L} / \mathrm{min}$ $\mathrm{H}_{2}$ and $1.75 \mathrm{~L} / \mathrm{min} \mathrm{Ar}$, and the other was just $\mathrm{H}_{2}$ at a flow rate of $3.5 \mathrm{~L} / \mathrm{min}$.

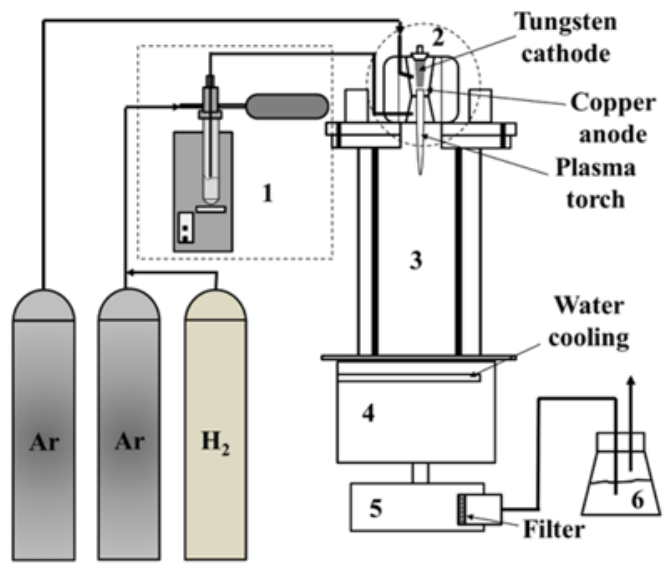

Fig. 1. A schematic of the plasma reactor system. (1) powder feeding system, (2) plasma gun, (3) reactor chamber, (4) cooling chamber, (5) powder collector, and (6) scrubber.

\section{Analysis methods}

The nanoceria products were subjected to several types of instrumental analysis. $\mathrm{X}$-ray powder diffraction (XRD) analysis was conducted using Rigaku D/Max-2200V 
$\mathrm{X}$-ray diffractometer with $\mathrm{Cu} \mathrm{K} \alpha$ radiation $(\lambda=1.5406 \AA)$ from $10.00^{\circ}$ to $90.00^{\circ}$ at a rate of $0.02 \%$ second. SEM images were taken by FEI Quanta 600 FEG, USA, while TEM images were collected by JEOL USA JEM-2800. The surface binding energy was obtained using a Kratos Axis Ultra DLD XPS instrument. Raman spectra were recorded using an R3000 QE Raman spectrometer (PhotoniTech, Singapore) with a $785 \mathrm{~nm}$ laser for excitation in the backscattering geometry.

\section{Results and discussion}

\section{$X R D$ results}

Results of the XRD analysis performed on the product nanoceria are shown in Fig. 2. Firstly, $\mathrm{CeO}_{2}$ diffraction peaks (PDF \# 04-0593) represent a face-centered cubic (fcc) structure. The XRD patterns for the samples obtained at $25 \mathrm{~kW}$ plasma power with a $3.5 \mathrm{~L} / \mathrm{min}$ Ar flow as the carrier gas and at $20 \mathrm{~kW}$ plasma power with a $3.5 \mathrm{~L} / \mathrm{min}$ hydrogen flow show somewhat different patterns compared with the other samples: Around the peaks for the fcc crystal faces (111), (200), (220) and (311), small peaks marked with triangles are present for these two samples, which were determined to represent $\mathrm{CeO}_{1.66}$ (PDF\# 89-8434). This means that a more reduced cerium sub-oxide phase/crystal was formed under the above conditions than the other samples.

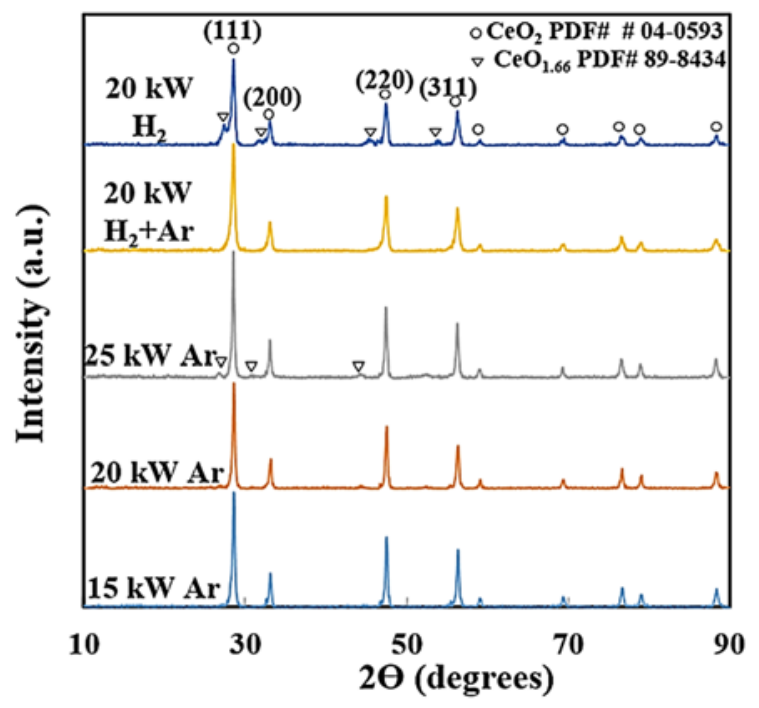

Fig. 2. XRD patterns of nanoceria synthesized under different conditions.

The crystal sizes calculated from the XRD results using the following Scherrer equation [37] and other crystal information are listed in Table 1:

$$
D=K \lambda /(\beta \cos \theta)
$$

In this equation, $D$ represents the crystallite size, $K$ the Scherrer constant $(0.89), \lambda$ the wavelength of the X-ray radiation (1.5418 $\AA$ ), $\beta$ the full width at half maximum (FWHM), and $\theta$ the diffraction angle. 
The results listed in Table 1 show that the crystal sizes of the nanoceria powders obtained with only Ar as the carrier gas were similar, and the crystal sizes of the two samples produced with the carrier gases containing hydrogen were of the same average size and smaller than that of the nanoceria synthesized by using only argon as the carrier gas.

Table 1 Crystal information of nanoceria products.

\begin{tabular}{lccccc}
\hline $\begin{array}{l}\text { Experimental } \\
\text { conditions }\end{array}$ & $\begin{array}{c}\text { Size } \\
(111), \mathrm{nm}\end{array}$ & $\begin{array}{c}\text { Size } \\
(220), \mathrm{nm}\end{array}$ & $\begin{array}{c}\text { Size } \\
(311), \mathrm{nm}\end{array}$ & $\begin{array}{c}\text { Average size, } \\
\mathrm{nm}\end{array}$ & Lattice parameter, $\AA$ \\
\hline $15 \mathrm{~kW}, \mathrm{Ar}$ & 23.2 & 26.6 & 27.2 & 25.7 & 5.4124 \\
$20 \mathrm{~kW}, \mathrm{Ar}$ & 25.5 & 26.2 & 25.4 & 25.7 & 5.4099 \\
$25 \mathrm{~kW}, \mathrm{Ar}$ & 26.7 & 26.3 & 27.5 & 26.8 & 5.4208 \\
$20 \mathrm{~kW}, \mathrm{H}_{2}+\mathrm{Ar}$ & 18.2 & 19.9 & 20.7 & 19.6 & 5.4199 \\
$20 \mathrm{~kW}, \mathrm{H}_{2}$ & 16.7 & 20.9 & 21.1 & 19.6 & 5.4043 \\
\hline
\end{tabular}

SEM and TEM images

The SEM micrographs of $\mathrm{CeCO}_{3} \mathrm{OH}$ and nanoceria products are shown in Fig. 3. The images show the particle sizes of nanoceria obtained under different conditions are similar in the range of $40-80 \mathrm{~nm}$.

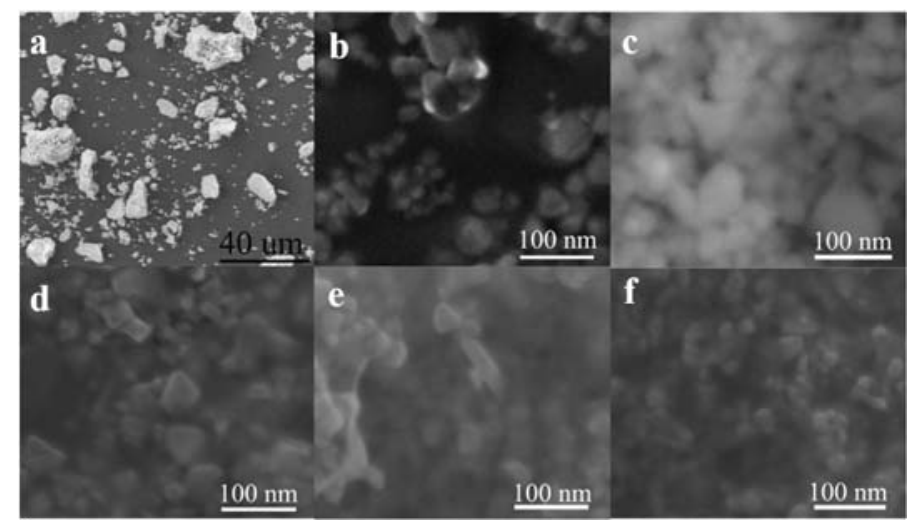

Fig. 3. SEM images of nanoceria samples. $\mathrm{A}-\mathrm{CeCO} \mathrm{OH}_{3} \mathrm{OH}-15 \mathrm{~kW}$ with argon only, $c-20 \mathrm{~kW}$ with argon only, $d-25 \mathrm{~kW}$ with argon only, $e-20 \mathrm{~kW}$ with argon + hydrogen (1:1), $f-15 \mathrm{~kW}$ with hydrogen only.

The TEM and high-resolution TEM (HRTEM) images of nanoceria powders are shown in Fig. 4. Most particles are of irregular shape, but some particles are triangular (Fig. 4d), which was reported to form after high-temperature exposure [38].

The average particle sizes were measured as $40 \mathrm{~nm}, 54 \mathrm{~nm}$, and $61 \mathrm{~nm}$, respectively, for the $15 \mathrm{~kW}, 20 \mathrm{~kW}$ and $25 \mathrm{~kW}$ experiments with argon only as the carrier gas. Increasing plasma power provided a higher temperature and a larger particle size $[28,36]$. The average particle size of the product obtained with a plasma power of $20 \mathrm{~kW}$ with the argon+hydrogen (1:1) mixture as the carrier gas was $57 \mathrm{~nm}$, while it increased to $60 \mathrm{~nm}$ when the only hydrogen was used as the carrier gas. 
The spacing of lattice fringes of Fig. $4 \mathrm{~d}$ was measured at $0.19 \mathrm{~nm}$, a value for (220) $\mathrm{CeO}_{2}$ crystal face. The HRTEM image in Fig. 4e shows a lattice spacing of 0.32 $\mathrm{nm}$ of the (111) face of ceria. This is the most stable [39] and least active face [13].

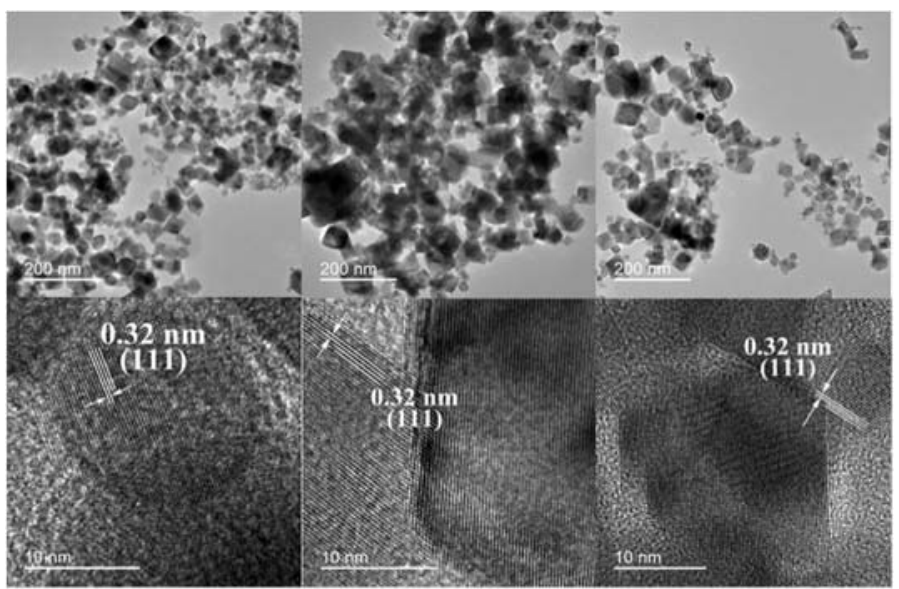

a b c

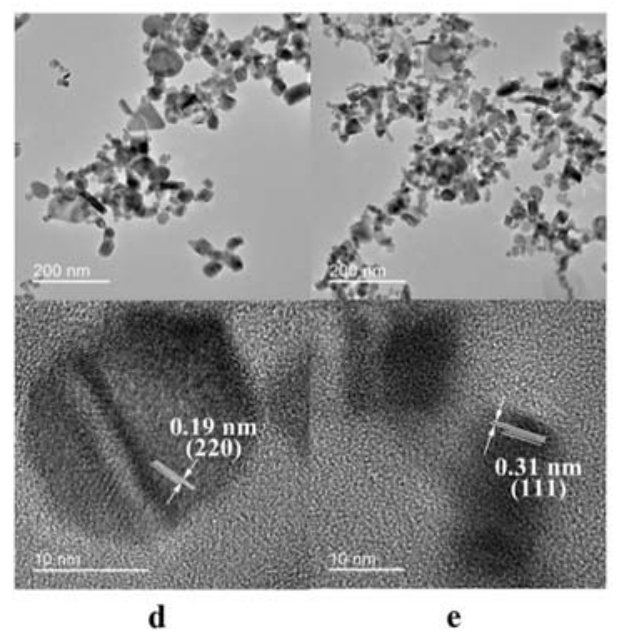

Fig. 4. TEM and HRTEM images of nanoceria samples. $A-15 \mathrm{~kW}$ with argon only, $b-$ $20 \mathrm{~kW}$ with argon only, $c-25 \mathrm{~kW}$ with argon only, $d-20 \mathrm{~kW}$ with argon + hydrogen (1:1), e - $15 \mathrm{~kW}$ with hydrogen only.

\section{Raman spectra}

Raman spectroscopy yields information about the interaction between the ions [40] and has been used for examining ceria or ceria-based materials in terms of defects and oxygen vacancies [40-43]. The Raman spectroscopy results for the synthesized ceria samples are shown in Fig. 5.

For single crystal ceria, the Raman peak located at $466.0 \mathrm{~cm}^{-1}$ is due to the $\mathrm{F}_{2 \mathrm{~g}}$ mode of vibration, which represents the symmetric stretching of Ce-8O [40]. This mode 
is sensitive to any disorder in the oxygen sub-lattice resulting from heat, doping, or grain-size induced effects. In Fig. 5 it is seen that for each sample there was a peak near but below $466.0 \mathrm{~cm}^{-1}$, and it is shown in the magnified figure that all nanoceria powders had a downshifted peak from $466.0 \mathrm{~cm}^{-1}$. The largest downshift of $10.5 \mathrm{~cm}^{-1}$ was found for nanoceria synthesized at $25 \mathrm{~kW}$ with $\mathrm{Ar}$ as the carrier gas. The downshift increased with plasma power, from $7.9 \mathrm{~cm}^{-1}$ to 10.5 as the power increased from 15 to $25 \mathrm{~kW}$ with $\mathrm{Ar}$ as the carrier gas. The downshift also increased with hydrogen addition in the carrier gas from $7.9 \mathrm{~cm}^{-1}$ to $9.6 \mathrm{~cm}^{-1}$ as hydrogen concentration changed from 0 to $100 \%$ under $20 \mathrm{~kW}$ power.

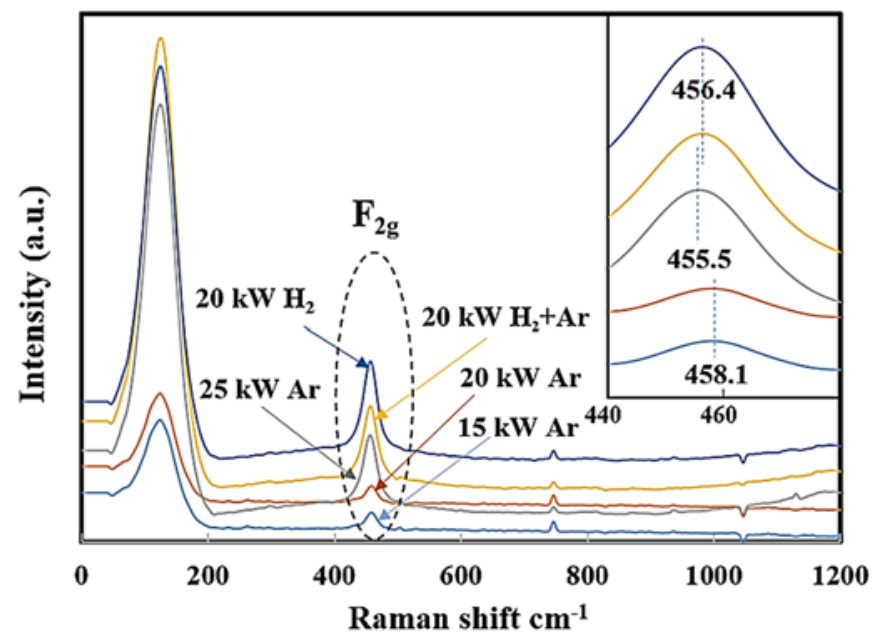

Fig. 5. Raman spectra of nanoceria synthesized under different conditions.

The downshift of Raman spectra occurs when the oxygen vacancies form upon the reduction of $\mathrm{Ce}^{4+}$ (ionic radius $0.970 \AA$ ) to $\mathrm{Ce}^{3+}(1.143 \AA$ ), in which two trivalent cerium ions replace a tetravalent cerium ion due to the lattice expansion and mode softening [43]. The relationships between the increase in vibration frequency and the changes in the lattice parameter and lattice volume are given by [41, 43]

$$
\Delta \omega=-3 \gamma \omega\left(\Delta a / a_{o}\right)=-\gamma \omega\left(\Delta V / V_{o}\right)
$$

where $\omega$ is the vibration frequency, $\gamma$ is the Grüneisen parameter for the $F_{2 g}$ mode (1.24, assumed to be independent of temperature), $\Delta a$ is the increase in lattice parameter, $a_{o}$ is the reference lattice parameter, $\Delta V$ is the volume change and $V_{o}$ is the reference volume of the lattice. The reduced ion $\mathrm{Ce}^{3+}$ has a longer ionic radius than $\mathrm{Ce}^{4+}$, which is partially offset by the effective compression due to the loss of $\mathrm{O}^{2-}(1.380$ $\AA$ ) and the creation of oxygen vacancies (1.164 $\AA)$ [44]. This results in the overall changes in lattice parameter as shown in Table 1. 
The relationship between $x$ in $\mathrm{CeO}_{2-\mathrm{x}}$ and $\Delta V / V_{o}$ is essentially linear, as follows $[43,45]$ :

$$
x=-10\left(\Delta a / a_{o}\right)=-3.3\left(\Delta V / V_{o}\right)
$$
[43]:

Then, based on Eqs.(2) and (3), $x$ for the non-stoichiometric ceria is given by

$$
x=2.66(\Delta \omega / \omega)
$$

According to Eq. (4), the chemical formulas for the samples with downshifts of $10.5 \mathrm{~cm}^{-1}, 9.6 \mathrm{~cm}^{-1}$, and $7.9 \mathrm{~cm}^{-1}$ were determined, respectively, to be $\mathrm{CeO}_{1.941}, \mathrm{CeO}_{1.946}$, and $\mathrm{CeO}_{1.956}$. These results are in agreement with those of Gilman and co-workers [32], who obtained nonstoichiometric ceria $\mathrm{CeO}_{1.940 \pm 0.005}$ by treating ceria with air plasma.

\section{XPS analysis}

This surface-sensitive (top 0 to $10 \mathrm{~nm}$ ) spectroscopic technique measures the elemental composition and the chemical and electronic states of elements in a solid. XPS analysis has been widely used to analyze the Ce3d state of cerium ions, which offers information on $\mathrm{Ce}^{3+}$ and $\mathrm{Ce}^{4+}$. The three states of $\mathrm{Ce}^{4+}$, including $\mathrm{Ce} 3 \mathrm{~d}^{9} 4 \mathrm{f}^{0} \mathrm{O} 2 \mathrm{p}^{6}$, $\mathrm{Ce} 3 \mathrm{~d}^{9} 4 \mathrm{f}^{1} O \mathrm{p}^{5}$ and $\mathrm{Ce} 3 \mathrm{~d}^{9} 4 \mathrm{f}^{2} \mathrm{O} 2 \mathrm{p}^{4}$, are expressed as $\mathrm{u}^{\prime \prime}\left(v^{\prime \prime \prime}\right)$, u" $\left(v^{\prime \prime}\right)$ and $\mathrm{u}(v)$, respectively, for $\mathrm{Ce} 3 \mathrm{~d}_{3 / 2}\left(\mathrm{Ce} 3 \mathrm{~d}_{5 / 2}\right)$. The two states of $\mathrm{Ce}^{3+}$ including $\mathrm{Ce} 3 \mathrm{~d}^{9} 4 \mathrm{f}^{1} \mathrm{O} 2 \mathrm{p}^{6}$ and $\mathrm{Ce} 3 \mathrm{~d}^{9} 4 \mathrm{f}^{2} \mathrm{O} 2 \mathrm{p}^{5}$ are expressed as $\mathrm{u}^{\prime}\left(v^{\prime}\right)$ and $\mathrm{u} 0\left(v_{0}\right)$ for $\mathrm{Ce} 3 \mathrm{~d}_{3 / 2}\left(\mathrm{Ce} 3 \mathrm{~d}_{5 / 2}\right)$ [16]. In Fig. 6a, the deconvoluted peaks of $\mathrm{Ce}^{4+}$ include $v(882 \pm 0.1 \mathrm{eV}), v^{\prime \prime}(886 \pm 0.2 \mathrm{eV}), v^{\prime \prime \prime}(898 \pm$ $0.1 \mathrm{eV}), \mathrm{u}(900.5 \pm 0.1 \mathrm{eV}), \mathrm{u}^{\prime \prime}(907.1 \pm 0.1 \mathrm{eV})$ and u"' $(916.2 \pm 0.1 \mathrm{eV})$, and those of $\mathrm{Ce}^{3+}$ are represented by $v_{0}(879 \pm 0.3 \mathrm{eV}), v^{\prime}(885.2 \pm 0.1 \mathrm{eV}), \mathrm{u}_{0}(897.9 \pm 0.3 \mathrm{eV})$ and $\mathrm{u}^{\prime}$ $(903.3 \pm 0.1 \mathrm{eV})$.

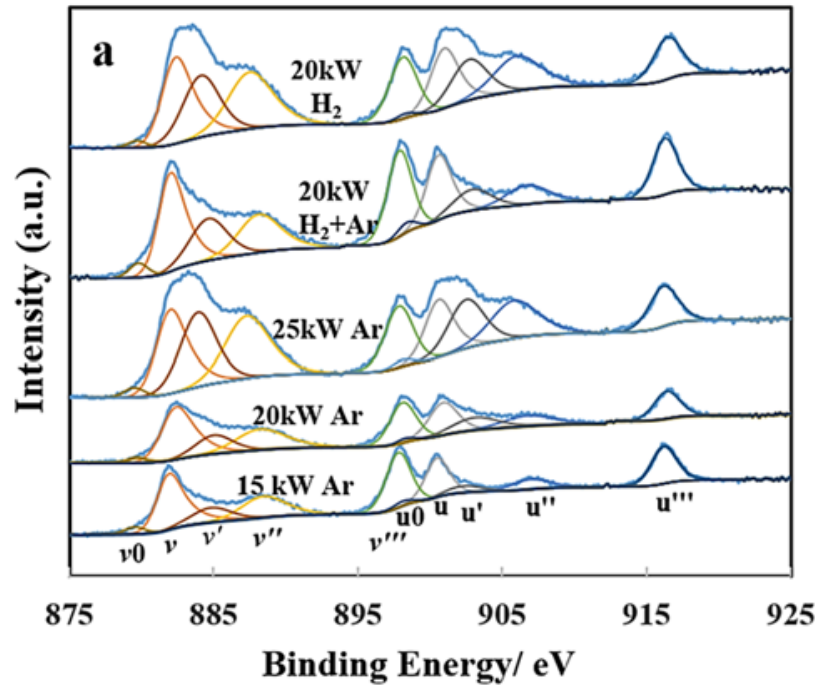




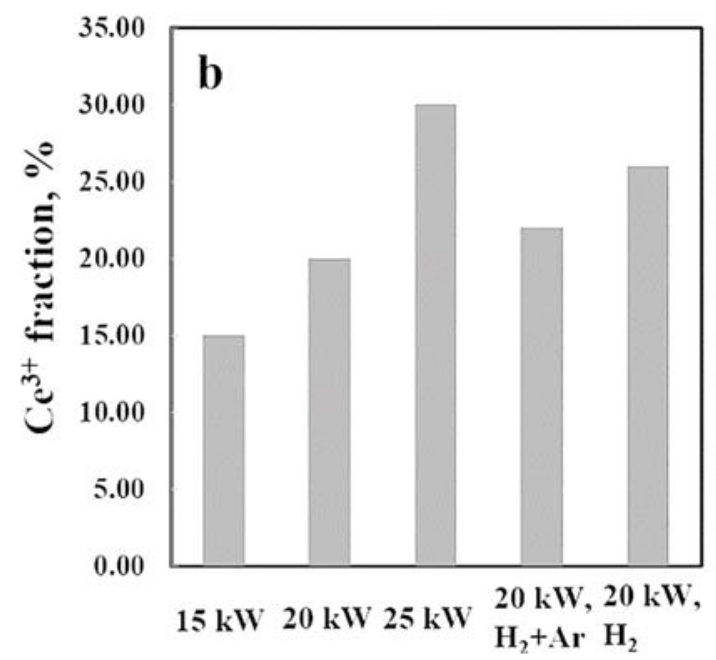

Fig. 6. XPS spectra of nanoceria produced under different conditions. (a) Ce3d patterns and deconvoluted peaks, and (b) $\mathrm{Ce}^{3+}$ fractions.

The $\mathrm{u}^{\prime}$ and $v^{\prime}$ peaks of $\mathrm{Ce}^{3+}$ become more intense with increasing plasma power and hydrogen addition, indicating an increasing fraction of $\mathrm{Ce}^{3+}$ on the ceria surface.

The $\mathrm{Ce}^{3+}$ fractions determined by the following equation [46] are shown in Fig. 6b:

$$
\frac{C e^{3+}}{\left(C e^{3+}+C e^{4+}\right)}=\frac{\operatorname{area}\left(v_{0}, u_{0}, v^{\prime}, u^{\prime}\right)}{\text { total area }}
$$

Results show that the $\mathrm{Ce}^{3+}$ fractions of nanoceria synthesized at $15 \mathrm{~kW}, 20 \mathrm{~kW}$ and $25 \mathrm{~kW}$ with argon as the carrier gas was 15, 20, and $30 \%$, respectively. The nanoceria synthesized at $20 \mathrm{~kW}$ with a 1:1 argon/hydrogen mixture had a $\mathrm{Ce}^{3+}$ fraction of $22 \%$ while it was $26 \%$ for the nanoceria obtained with hydrogen as the carrier gas.

As mentioned before, XPS analyzes a surface layer (top 0-10 nm), and thus the results from this examination determined that the chemical formulas of the surface layer were $\mathrm{CeO}_{1.925}, \mathrm{CeO}_{1.900}$ and $\mathrm{CeO}_{1.850}$, respectively, for ceria synthesized at $15 \mathrm{~kW}, 20$ $\mathrm{kW}$ and $25 \mathrm{~kW}$ with argon and $\mathrm{CeO}_{1.890}$ and $\mathrm{CeO}_{1.870}$, respectively, for nanoceria produced at $20 \mathrm{~kW}$ with $1: 1 \mathrm{Ar} / \mathrm{H}_{2}$ and pure $\mathrm{H}_{2}$ as the carrier gas.

Formation of non-stoichiometric nanoceria and oxygen vacancies

The formation of non-stoichiometry and oxygen vacancies in samples prepared in thermal plasma is summarized in Fig. 7. The crystal structure was constructed by the VESTA software [47]. $\mathrm{Ce}_{2} \mathrm{O}_{3}$ has a hexagonal (space group: $\mathrm{p} \overline{3} \mathrm{ml}$ ) structure while $\mathrm{CeO}_{2}$ has a face-centered cubic structure (space group: $\mathrm{Fm} \overline{3} \mathrm{~m}$ ).

A plasma torch can generate a temperature as high as $11,500 \mathrm{~K}$ at $16 \mathrm{~kW}$ [29]. Due to the very high temperature, cerium carbonate hydroxide can be decomposed to nanoceria, according to the following reaction:

$$
4 \mathrm{CeCO}_{3} \mathrm{OH} \rightarrow 4 \mathrm{CeO}_{2}+3 \mathrm{CO}_{2}+\mathrm{H}_{2} \mathrm{O}+\mathrm{CO}+\mathrm{H}_{2}
$$


The $\mathrm{CO}_{2}$ and $\mathrm{H}_{2} \mathrm{O}$ produced provide enough oxidants to oxidize all $\mathrm{Ce}^{3+}$ to $\mathrm{Ce}^{4+}$ even without external supply, and nanoceria forms during the decomposition process by the rapid heating to a high temperature by thermal plasma.

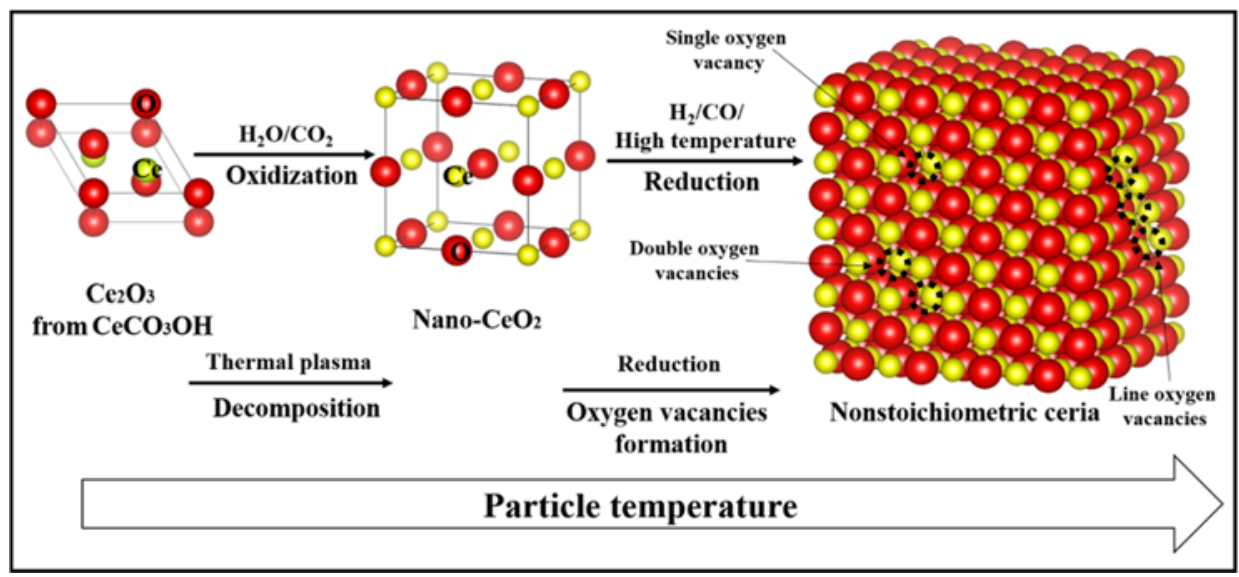

Fig. 7. Formation of non-stoichiometry and oxygen vacancies in thermal plasma.

As the powder is further heated by plasma, ceria begins to be reduced. It has been reported [48] that at high temperatures, oxygen starts to be released from ceria around $1600{ }^{\circ} \mathrm{C}$, according to

$$
\begin{aligned}
& \mathrm{CeO}_{2} \rightarrow \mathrm{CeO}_{2-x}+0.5 x \mathrm{O}_{2} \\
& \mathrm{CeO}_{2}+x \mathrm{H}_{2} \rightarrow \mathrm{CeO}_{2-x}+x \mathrm{H}_{2} \mathrm{O} \\
& \mathrm{CeO}_{2}+x \mathrm{CO} \rightarrow \mathrm{CeO}_{2-x}+x \mathrm{CO}_{2}
\end{aligned}
$$

Figure $6 \mathrm{~b}$ indicates that the nanoceria synthesized with hydrogen in the carrier gas had a higher $\mathrm{Ce}^{3+}$ fraction than without it. The $\mathrm{CeO}_{1.66}$ phase, which has a cubic superstructure $[49,50]$, was present at a higher temperature or under a more reducing atmosphere, according to the XRD results.

The crystal structure of non-stoichiometric nanoceria shown in Fig. 7 indicates different types of oxygen vacancies, including single, double and line vacancies. Ceria is reported to maintain a fluorite structure even after incorporating up to $14 \%$ oxygen vacancies [14]. When oxygen is released, the two electrons previously occupying the $p$ orbitals of the departed oxygen redistribute in the solid and an oxygen vacancy is formed [51]. The energies associated with the formation of singly and doubly ionized vacancies were determined to be $\sim 4.1$ and $4.7 \mathrm{eV}$, respectively [14]. Nörenberg and coworkers [52] calculated that oxygen vacancies are more stable at the surface than in the bulk, and their calculation suggested $0.19 \mathrm{eV}$ energy gain for per vacancy pair if two initially separated oxygen vacancies form a line structure.

In non-stoichiometric ceria the concentration of oxygen vacancies is related to the deviation from stoichiometry $x$ in $\mathrm{CeO}_{2-x}$ by the following equation [53]: 


$$
n V O^{*}=4 x / a 3
$$

where $a$ is the lattice parameter of $\mathrm{CeO}_{2-\mathrm{x}}, n \mathrm{VO}^{*}$ is the concentration of oxygen vacancies per cubic centimeter. Based on the Raman results, $x$ was calculated to lie in the range of $0.044-0.059$ for the ceria samples synthesized in this work. Thus, the corresponding $n \mathrm{VO}^{*}$ values range in $1.11-1.49 \times 1021 \mathrm{~cm}^{3}$ depending on experimental conditions. The XPS results yield the oxygen vacancies on ceria surface to be considerably higher in the range of $1.89-3.29 \times 1021 \mathrm{~cm}^{3}$.

Numerous oxygen vacancies present in the non-stoichiometric ceria are related to many unique properties of ceria, such as the oxygen storage capacity [16]. $\mathrm{CeO}_{2-x}$ ceramics show a significantly enhanced n-type overall conductivity [54], and oxygen vacancies are also associated with the magnetism of ceria [55]. These properties of oxygen vacancies make the plasma synthesized non-stoichiometric ceria promising for various applications.

\section{Conclusions}

Non-stoichiometric nanoceria was successfully synthesized by thermal plasma from cerium carbonate hydrate. In this blue nanoceria power, $\mathrm{CeO}_{1.66}$ was present when synthesized with $25 \mathrm{~kW}$ plasma power and argon carrier gas or $20 \mathrm{~kW}$ with hydrogen. The average size of these nanoceria particles produced under different conditions was approximately $60 \mathrm{~nm}$ as measured from the TEM images. Most of the particles were irregular, but some triangle-shaped particles were also present. Raman spectra showed a noticeable downshift of the $\mathrm{F}_{2 \mathrm{~g}}$ mode of vibration in these nanoceria particles relative to the peak for single crystal ceria located at $466.0 \mathrm{~cm}^{-1}$. The downshift was caused by the increase in the cerium ionic radius accompanying the reduction of $\mathrm{Ce}^{4+}$ to $\mathrm{Ce}^{3+}$ and measured to be in the range of $10.5-7.9 \mathrm{~cm}^{-1}$, depending on the reduction degree. The XPS results also showed significant evidence for the high degree of reduction, in which the $\mathrm{Ce}^{3+}$ fraction on the ceria surface was in the range of $15-30 \%$. Both the Raman and XPS analyses indicated high concentrations of oxygen vacancies in the synthesized nanoceria. The formation of oxygen vacancies in thermal plasma proceeded by the initial oxidation of cerium carbonate hydroxide to ceria at a lower temperature followed by the reduction of the oxidation product $\mathrm{CeO}_{2}$ at a higher temperature and the reducing agent. This investigation proved that thermal plasma represents a useful method for the synthesis of non-stoichiometric nanoceria with a high level of oxygen vacancies, which makes it a promising nanomaterial for oxygen storage, semi-conductive ceramic or magnetic applications.

\section{Acknowledgments}

The authors thank William Davis Mace with the Department of Geology \& Geophysics for help with the XRD analysis and Dr. Paulo Perez and Dr. Brian Van Devener with the University of Utah Nanofab for assistance with the SEM, TEM and XPS analyses. The financial support from NSF/U.S.-Egypt Joint Science and Technology Board under Grant No. IIA-1445577 is gratefully acknowledged. Yuan-Pei Lan expresses his gratitude to China Scholarship Council (CSC No. 201406050057) for the financial support he received for his stay at the University of Utah. 


\section{References}

[1] K. Reed, A. Cormack, A. Kulkarni, M. Mayton, D. Sayle, F. Klaessig, B. Stadler: Environ Sci: Nano, 1 (2014) 390-405.

[2] J. Kašpar, P. Fornasiero, M. Graziani: Catal Today, 50 (1999) 285-298.

[3] N. Gokon, T. Suda, T. Kodama: Energy, 90 (2015) 1280-1289.

[4] M. Nabavi, O. Spalla, B. Cabane, Surface chemistry of nanometric ceria particles in aqueous dispersions, J Colloid Interface Sci, 160 (1993) 459-471.

[5] P.V. Dandu, B. Peethala, S. Babu: J Electrochem Soc, 157 (2010) H869-H874.

[6] H. Yoshida, K. Miura, J.i. Fujita, T. Inagaki: J Am Ceram Soc, 82 (1999) 219-221.

[7] K. Maca, M. Trunec, J. Cihlar: Ceram Int, 28 (2002) 337-344.

[8] W. Gao, Z. Zhang, J. Li, Y. Ma, Y. Qu: Nanoscale, 7 (2015) 11686-11691.

[9] L. Qiu, F. Liu, L. Zhao, Y. Ma, J. Yao: Appl Surf Sci, 252 (2006) 4931-4935.

[10]X. Chen, L. Liu, Y.Y. Peter, S.S. Mao: Science, 331 (2011) 746-750.

[11]K. Mudiyanselage, H.Y. Kim, S.D. Senanayake, A.E. Baber, P. Liu, D. Stacchiola: Phys Chem Chem Phys, 15 (2013) 15856-15862.

[12] J.W. Dawicke, R.N. Blumenthal: J Electrochem Soc, 133 (1986) 904-909.

[13] X. Liu, K. Zhou, L. Wang, B. Wang, Y. Li: J Am Chem Soc, 131 (2009) 31403141.

[14]H. Tuller, A. Nowick: J Electrochem Soc, 126 (1979) 209-217.

[15]R. Blumenthal, R. Hofmaier: J Electrochem Soc, 121 (1974) 126-131.

[16]K. Wang, Y. Chang, L. Lv, Y. Long: Appl Surf Sci, 2015, 351: 164-168.

[17] J. Gerblinger, W. Lohwasser, U. Lampe, H. Meixner: Sens Actuators, B, 26 (1995) 93-96.

[18]H. Hojo, T. Mizoguchi, H. Ohta, S.D. Findlay, N. Shibata, T. Yamamoto, Y. Ikuhara: Nano Lett, 10 (2010) 4668-4672.

[19] M. Hirano, M. Inagaki: J Mater Chem, 10 (2000) 473-477.

[20]M. Darroudi, M. Sarani, R.K. Oskuee, A.K. Zak, M.S. Amiri: Ceram Int, 40 (2014) 2863-2868.

[21]M. Darroudi, M. Sarani, R.K. Oskuee, A.K. Zak, H.A. Hosseini, L. Gholami: Ceram int, 40 (2014) 2041-2045.

[22] M. Kamruddin, P. Ajikumar, R. Nithya, A. Tyagi, B. Raj: Scr Mater, 50 (2004) 417-422.

[23]R. Purohit, B. Sharma, K. Pillai, A. Tyagi: Mater Res Bull, 36 (2001) 2711-2721.

[24] Y. He, B. Yang, G. Cheng: Mater Lett, 57 (2003) 1880-1884.

[25] M. Hirano, E. Kato: J Am Ceram Soc, 82 (1999) 786-788.

[26] J.E. Lee, S.-M. Oh, D.-W. Park: Thin Solid Films, 457 (2004) 230-234.

[27] X. Wang, J.-G. Li, H. Kamiyama, M. Katada, N. Ohashi, Y. Moriyoshi, T. Ishigaki: J Am Ceram Soc, 127 (2005) 10982-10990.

[28]T. Ryu, Y.J. Choi, S. Hwang, H.Y. Sohn, I. Kim: J Am Ceram Soc, 93 (2010) 3130-3135.

[29] P. Ananthapadmanabhan, T. Thiyagarajan, K. Sreekumar, N. Venkatramani: Scr Mater, 50 (2004) 143-147.

[30]L. Tong, R.G. Reddy: MRS Bulletin, 41 (2006) 2303-2310.

[31] A. Fathalizadeh, T. Pham, W. Mickelson, A. Zettl: Nano letters, 14 (2014) 48814886.

[32] W. Gilman, P. Seabaugh, D. Sullenger: Science, 160 (1968) 1239-1239.

[33]X. Wu, H. Niu, S. Fu, J. Song, C. Mao, S. Zhang, D. Zhang, C. Chen: J Mater Chem A, 2 (2014) 6790-6795. 
[34] S. Yin, Y. Minamidate, S. Tonouchi, T. Goto, Q. Dong, H. Yamane, T. Sato: RSC Adv, 2 (2012) 5976-5982.

[35] Y.P. Lan, H.Y. Sohn, Y. Mohassab, Q. Liu, B. Xu: J Am Ceram Soc, 100 (2017) 1863-1875.

[36] T. Ryu, H. Sohn, K.S. Hwang, Z.Z. Fang: J Alloys Compd, 481 (2009) 274-277.

[37]P. Scherrer: Göttinger Nachrichten, 2 (1918) 98-100.

[38] X. Feng, D.C. Sayle, Z.L. Wang, M.S. Paras, B. Santora, A.C. Sutorik, T.X. Sayle, Y. Yang, Y. Ding, X. Wang: Science, 312 (2006) 1504-1508.

[39]F. Esch, S. Fabris, L. Zhou, T. Montini, C. Africh, P. Fornasiero, G. Comelli, R. Rosei: Science, 309 (2005) 752-755.

[40]I. Kosacki, V. Petrovsky, H.U. Anderson, P. Colomban: J Am Ceram Soc, 85 (2002) 2646-2650.

[41] J. McBride, K. Hass, B. Poindexter, W. Weber: J Appl Phys, 76 (1994) 2435-2441.

[42]Z. Wu, M. Li, J. Howe, H.M. Meyer III, S.H. Overbury: Langmuir, 26 (2010) $16595-16606$.

[43] Y. Lee, G. He, A.J. Akey, R. Si, M. Flytzani-Stephanopoulos, I.P. Herman: J Am Ceram Soc, 133 (2011) 12952-12955.

[44] S.J. Hong, A.V. Virkar: J Am Ceram Soc, 78 (1995) 433-439.

[45] S. Bishop, K. Duncan, E. Wachsman: Electrochim Acta, 54 (2009) 1436-1443.

[46]H. Borchert, Y.V. Frolova, V.V. Kaichev, I.P. Prosvirin, G.M. Alikina, A.I. Lukashevich, V.I. Zaikovskii, E.M. Moroz, S.N. Trukhan, V.P. Ivanov: J Phys Chem, 109 (2005) 5728-5738.

[47] K. Momma, F. Izumi: J Appl Crystallogr, 44 (2011) 1272-1276.

[48] W.C. Chueh, C. Falter, M. Abbott, D. Scipio, P. Furler, S.M. Haile, A. Steinfeld: Science, 330 (2010) 1797-1801.

[49] E. Kümmerle, G. Heger: J Solid State Chem, 147 (1999) 485-500.

[50]J.L. Da Silva: Phys Rev B, 76 (2007) 193108.

[51] H.F. Wang, H.Y. Li, X.Q. Gong, Y.L. Guo, G.Z. Lu, P. Hu: Phys Chem Chem Phy, 14 (2012) 16521-16535.

[52]H. Nörenberg, G. Briggs: Phys Rev Lett, 79 (1997) 4222.

[53] G. VanHandel, R. Blumenthal: J Electrochem Soc, 121 (1974) 1198-1202.

[54] S. Kim, R. Merkle, J. Maier: Surf Sci, 549 (2004) 196-202.

[55] V. Fernandes, R. Mossanek, P. Schio, J. Klein, A. De Oliveira, W. Ortiz, N. Mattoso, J. Varalda, W. Schreiner, M. Abbate: Phys Rev B, 80 (2009) 035202. 